\title{
Associativismo como ferramenta de internacionalização de empresas: estudo de caso de uma associação comercial de Santa Catarina
}

\author{
Gisela Hodecker ${ }^{1}$ \\ Jeferson Lana² \\ Suzete Antonieta Lizote ${ }^{3}$ \\ Miguel Angel Verdinelli ${ }^{4}$
}

\section{RESUMO}

Este estudo de caso pretende apresentar a situação do Núcleo de Comércio Exterior da Associação Empresarial de uma cidade de Santa Catarina, em relação às estratégias do grupo e ao associativismo. A criação de núcleos setoriais para uma Associação proporciona o estímulo ao debate entre empresas do mesmo ramo que possuem interesses em comum para discutir acontecimentos e planejar estratégias a adotar. Em relação ao Núcleo de Comércio Exterior, este possui atualmente 15 participantes e os encontros acontecem mensalmente, visando o debate e troca de experiências na área. Assim, neste estudo serão apresentados os principais itens do planejamento estratégico elencados pelo grupo, bem como as ações realizadas e a realizar, com o objetivo de apresentar o associativismo como uma ferramenta para internacionalização das empresas. Quanto à revisão da literatura existente, o foco foi direcionado a dois itens principais: internacionalização, em suas diferentes modalidades, e também o associativismo. Quanto à pesquisa de campo, foram feitas entrevistas com representantes do núcleo, questionários com as empresas participantes e pesquisa bibliográfica para relacionar a prática do núcleo com os estudos existentes na área, utilizando livros, periódicos, meios eletrônicos e documentação fornecida pelas empresas. Como principal resultado considerou-se a evidência de que, para a amostra da população estudada, o associativismo é de grande relevância para os processos de internacionalização.

Palavras-chave: Estratégias Competitivas. Internacionalização de Empresas. Associativismo.

\footnotetext{
1 Acadêmica de Administração - Grupo Uniasselvi/Assevim

2 Mestrando em Administração - Univali

3 Doutoranda em Administração - Univali

4 Professor do PPGA - Univali
} 


\section{INTRODUÇÃO}

O associativismo é tema recorrente no ambiente corporativo. Estudos comprovam que a percepção por parte dos gestores é de que a união entre as empresas, na busca pelo bem comum, pode ser considerada uma ferramenta e até mesmo, uma estratégia de negócios (PORTER, 1989; BATEMAN; SNELL, 1998; GARCIA; LIMA; CARVALHO, 2010; MELÉNDEZ; HAWLEY; MCCORMICK, 2012).

A internacionalização de empresas também parece ser vista como uma possibilidade de ganhos de vantagem competitiva (PENROSE, 1959; LEVITT, 1983). Nesse sentido, pesquisas têm demonstrado que empresas que buscam o mercado externo tendem a conseguir melhores resultados mercadológicos, econômicos e financeiros (DUNNING, 1988; PENG, 2001; RUIGROK; WAGNER, 2003; FILATOTCHEV; STEPHAN; JINDRA, 2008)

No Brasil, foi na década de 90 que grandes alterações foram sentidas no cenário nacional, com a abertura da economia. "A liberação comercial foi o principal elemento de uma nova política de comércio exterior atrelada à política industrial: a retomada do desenvolvimento econômico deveria ser impulsionada pela busca de competição interna" (LOPEZ; GAMA, 2008, p. 207).

Em 2010, o Brasil foi o $20^{\circ}$ maior importador mundial, com o valor de US\$ 191 bilhões e participação de $1,2 \%$, sendo $45,4 \%$, importação de matérias primas. No que tange às exportações, o país ficou na $22^{a}$ posição, com US\$ 202 bilhões e participação de 1,3\%, sendo $50,4 \%$ de produtos industrializados. Os principais destinos das exportações brasileiras são China $(16,9 \%)$, EUA $(9,9 \%)$ e Argentina $(8,8 \%)$; e os principais produtos são os minérios (16,4\%), petróleo e combustíveis $(12,6 \%)$ e complexo de soja (10,7\%). Atualmente, 15.638 empresas exportam seus produtos, sendo $94 \%$ das empresas de grande porte, $4,1 \%$ médio porte, $1,0 \%$ pequeno porte e $0,1 \%$ pessoa física (BRASIL, 2011).

Nos dados consolidados divulgados pelo Ministério do Desenvolvimento, Indústria e Comércio Exterior para os meses de Janeiro a Junho de 2011, o Brasil registrou recorde na sua corrente de comércio: US $\$ 223,6$ bilhões, com saldo comercial de US\$13,0 bilhões.

O objetivo deste artigo, portanto, é estudar a internacionalização sob a perspectiva do associativismo como ferramenta estratégica. A seguir, serão brevemente revistos os conceitos teóricos sobre os temas propostos e, posteriormente, uma pesquisa empírica será apresentada.

\section{INTERNACIONALIZAÇÃO}

A internacionalização corporativa vem a ser a inserção no mercado externo, seja através de produtos ou serviços, e que permite diferentes formas de atuação de maior ou menor intensidade. Segundo a Fundação Dom Cabral (2011) "internacionalização é o processo de obtenção de parte ou totalidade do faturamento a partir de operações internacionais". Demais autores tratam da internacionalização como a ponte criada entre a empresa e o mercado externo, seja pelos produtos, processos produtivos, estrutura de propriedade ou mesmo de controle (HYMER, 1972; DUNNING, 1988; FILATOTCHEV; STEPHAN; JINDRA, 2008)

A inserção externa não deve ser feita, entretanto, sem o devido estudo do mercado pretendido. As empresas devem levar em consideração questões econômicas, de legislação, sociais e culturais, que são diferentes em cada país. Estas particularidades tornam cada região única e influenciam diretamente o consumidor (BRASIL, 2011).

O Ministério do Desenvolvimento, Indústria e Comércio Exterior separa este estudo por 'fatores', critérios que devem ser considerados para determinar possíveis mercados consumidores, a saber: fatores geográficos, sociopolíticos, econômicos, culturais e tecnológicos (BRASIL, 2011).

A Teoria de Uppsala afirma que a distância psíquica entre os países, ou seja, "as diferenças 
percebidas entre valores, práticas gerenciais e educação de dois países" (JOHANSON; VAHLNE, 1977, apud GARCIA; LIMA; CARVALHO, 2010, p. 212) é um fator de decisão para a internacionalização. Isto porque as empresas têm preferência por países mais semelhantes para iniciar este processo, com uma cultura próxima, para diminuir o grau de incerteza e, consequentemente, haver uma melhor aceitação.

Para isso, no entanto, cabe a cada organização analisar a sua própria capacidade de inserção e manutenção no mercado externo. Devem-se levar em consideração, também, dois elementos que fazem parte deste processo: o conhecimento e o comprometimento. Sendo considerado conhecimento, àquele relacionado "ao mercado-alvo" e comprometimento "o montante de recursos investidos em determinado mercado internacional e ao grau de especificidade desses recursos" (JOHANSON; VAHLNE, apud GARCIA; LIMA; CARVALHO, 2010, p. 213). Dentre as principais formas de internacionalização encontradas nas teorias contemporâneas, podem-se citar estas que seguem (HYMER, 1972; DUNNING, 1988; PENG, 2001; RUIGROK; WAGNER, 2003; PORTER, 2004; GARCIA; LIMA; CARVALHO, 2010):

\subsection{Exportação}

A forma mais básica de internacionalização é a exportação (direta ou indireta) - ou seja, a venda de produtos ao exterior. Nesta modalidade, a interação entre as empresas de diferentes países acontece de modo mais ameno (ABIT, 2011).

Lopez e Gama (2008) destacam a exportação brasileira como a principal forma de internacionalização, vista a importância econômica que esta atividade gera para a economia do país. Entre as vantagens destacadas pelos autores estão: a nova cultura, desenvolvimento de métodos administrativos e organizacionais, diversificação de mercado e consequente aperfeiçoamento mercadológico e assimilação de novas técnicas de produção e comercialização.

Um dos reflexos internos da exportação que pode ser destacado é a valorização da empresa e, principalmente, de sua marca. 0 fato de conseguir alcançar com eficácia mercados externos pode significar, aos olhos do cliente, a qualidade do produto ou serviço, bem como flexibilidade e capacidade de adaptação (ARMANDO, 2003; FILATOCHEV; STEPHAN; JINDRA, 2008).

\subsection{Consórcio de exportação}

O consórcio de exportação caracteriza-se pela união de empresas tendo como objetivo a exportação. É o agrupamento de empresas com interesses comuns, reunidas em uma entidade estabelecida juridicamente, sem fins lucrativos, na qual empresas parceiras tenham maneiras de trabalho conjugados e em cooperação, com objetivos comuns de melhoria da oferta exportável e de promoção de exportação (ABIT, 2011).

Ruigrok e Wagner (2003) e Armando (2003) destacam o consórcio de exportação como uma ferramenta estratégica para as pequenas e médias empresas que possuem maiores dificuldades para ingressar e, principalmente, permanecer no mercado externo, visto este ser mais complexo e exigente. Com o consórcio, de acordo com os autores, é possível, além de concentrar os esforços, também realizar rateio das despesas, reduzindo custos e otimizando as ações.

\subsection{Subsidiária própria no exterior}

Nesta modalidade, a empresa passa a manter uma filial em outro país. Bateman e Snell (1998) classificam como vantajosa esta modalidade no que se refere ao controle da empresa, que pode ser mais rígido com relação às ações em outro mercado. E ainda, citam as empresas, cuja vantagem competitiva é a tecnologia, como a subsidiária faz com que diminuam os riscos de se 
perder o controle. Como ponto negativo a destacar, os autores citam o custo. A instalação de uma subsidiária faz com que a empresa arque com todos os custos e riscos de entrada em um mercado internacional.

Com relação à administração, Porter (2004), e mesmo, Bateman e Snell (1998) informam que nos últimos anos têm-se utilizado administradores do país onde a empresa será instalada, ao invés do país nativo, pois consideram vantagem: disponibilidade, familiaridade com cultura e idioma e menor custo, pela não necessidade de deslocamento.

\subsection{Joint Venture}

A união de duas empresas, de países diferentes, geralmente forma uma terceira empresa, com o intuito de unir forças para um projeto em comum. A característica essencial do contrato de joint venture, conforme comentam Miranda e Maluf (2011) é a realização de um projeto comum entre empresas distintas. "Cada parte que compõe os pólos dessas associações deve trazer aquilo que possui de melhor, além disso, a transparência é essencial, pois a joint venture é a confiança entre as partes" (MIRANDA; MALUF, 2011, p.1).

Entre os principais benefícios de uma joint venture, podem ser citados: a troca de conhecimentos, a utilização da capacidade produtiva ou intelectual de outra empresa, os conhecimentos locais e culturais que uma empresa localizada no mercado alvo possui e, ainda, esta pode ser a única forma de inserção em determinado mercado, visto que, alguns locais podem possuir certas restrições e objeções com empresas estrangeiras (PENG, 2001; PORTER, 2004; MIRANDA; MALUF, 2011).

Como desvantagens têm-se o fato de que a empresa não detém o controle total da operação, devendo haver consenso entre elas em determinadas situações. Outra questão é a exposição do conhecimento/tecnologia/processo produtivo para uma outra empresa.

\subsection{Licenciamento}

Nesta modalidade as empresas licenciam suas marcas, modelos, processos de produção para outras empresas no exterior. Bateman e Snell (1998) definem o licenciamento internacional como um arranjo, onde o licenciado em um outro país compra os direitos de fabricação de um produto. Os autores citam como vantagem deste tipo de internacionalização, o fato de não ser necessário arcar com os custos de abertura em um país estrangeiro. Outras vantagens que podem ser destacadas são:

[...] superar barreiras contra produtos estrangeiros, com uma parcial fabricação local (reduzindo tanto as barreiras alfandegárias como a hostilidade do governo local, pois em muitos casos, a tecnologia incrementa empregos no país); proteger marcas e patentes registradas, porém não utilizadas (MINERVINI, 2001, p. 204).

Como principal desvantagem, Bateman e Snell (1998) citam a assimilação que o licenciado pode ter em relação ao processo de fabricação da mercadoria, e logo produzir com a mesma tecnologia e qualidade a sua própria marca.

\subsection{Investimento direto}

Caracteriza-se pelo investimento diretamente em empresas localizadas no exterior. De acordo com a Receita Federal do Brasil (2011), "o investimento direto é constituído quando o investidor detém $10 \%$ ou mais das ações ordinárias ou do direito a voto numa empresa". No âmbito acadêmico se atribui a Hymer (1972), em sua obra de 1976, a origem das teorias relativas ao investimento direto estrangeiro. 
A Receita Federal do Brasil (RFB) apresenta como objetivos das empresas que investem no exterior: "recuperar os custos fixos associados a mudanças tecnológicas, capturar parcela do mercado e participar do processo de abertura dos oligopólios nacionais" (RECEITA FEDERAL DO BRASIL, 2011).

\subsection{Franchising}

São as populares franquias. Uma empresa cede a um franqueado o direito de utilizar a sua marca, seu formato de negócio.

De acordo com a Associação Brasileira de Franquias (2010), após estudo realizado em parceria com a Escola Superior de Propaganda e Marketing (ESPM), foi verificada a existência de atualmente 700 unidades brasileiras de franquias em 49 países. A Argentina é o mercado com a maior presença de unidades, 144, seguida por Portugal (118), Estados Unidos (64), México (48) e Chile (36).

Com dados desta mesma pesquisa (ABF, 2010), na visão das empresas franqueadas, é necessário ter entre cinco e dez lojas no exterior para que seja justificado o investimento nas adaptações necessárias ao novo mercado, bem como tornar a marca conhecida e ter rentabilidade nos negócios. "Cerca de $80 \%$ das franquias exportadoras revelam que o faturamento externo não chega a $5 \%$ da operação. [...] 0 motivo da pouca arrecadação é resultado direto do baixo número de unidades implantadas por franquia", afirma Thelma Rocha, professora do Curso de Mestrado em gestão internacional da ESPM que conduziu a pesquisa (apud ABF, 2010).

Para Lampert (2011, p. 2), "o desenvolvimento de marcas nacionais tem incentivado a internacionalização de algumas companhias, que enxergam nas unidades estrangeiras a oportunidade de conquistar novos mercados". Desta forma, o autor considera como um dos maiores desafios à adaptação corporativa, as legislações e a cultura dos outros países.

\section{ASSOCIATIVISMO}

"Nenhum Homem é uma ilha". Esta frase de John Done, datada do século XVI, retrata uma realidade bastante discutida e estudada no ambiente organizacional. A ideia central é que as empresas passaram a ter consciência de que a coletividade pode agregar valor e diferencial competitivo e que a soma de esforços pode gerar melhores resultados. De acordo com Lynch (1994, p. 19) "empreendimentos que partilham da colaboração estão entre as formas mais antigas de atividade comercial. Porém, muito pouco foi desenvolvido para auxiliar aqueles que estejam considerando a formação de uma aliança comercial".

Fleury e Fleury (2003, apud GARCIA; LIMA; CARVALHO, 2010, p. 209) determinam como principal característica da economia do século XXI "a transição da eficiência individual para a eficiência coletiva. A competitividade, cada vez mais está relacionada ao desempenho de redes interorganizacionais e não de empresas isoladas".

Neste contexto encontra-se o associativismo, uma forma de atuação que vem atraindo cada vez mais adeptos. Cielo et al (2009, p.1) assim o descreve: "0 termo associativismo deriva de associações, pois remete ao sentimento de que os associados devem compartilhar, de repartir os dividendos e ajudar-se nas dificuldades". Para SEBRAE (2011, p. 3):

As associações representam um fórum legítimo para a discussão de temas relacionados ao universo das relações empresariais. Quando bem conduzidas, podem assumir uma postura de vanguarda e pioneirismo, reunindo especialistas de elevada qualificação para semear discussões e apontar caminhos para novas e instigantes questões. 
O Instituto Brasileiro de Associativismo define como uma "iniciativa 'Formal ou Informal' de grupos de pessoas físicas e ou jurídicas, que tem como objetivo principal, solucionar seus problemas comuns e gerar benefícios econômicos e sociais, que se isolada não conseguiria ou teria um custo elevado para resolução" o associativismo (IBRASS, 2011).

Este tipo de movimento pode abranger empresas, pessoas, órgãos e entidades que possuem interesses em comum, em busca da otimização de suas ações e benefícios, bem como a abrangência dos mesmos.

A mobilização de um grupo de pessoas da comunidade ou de empresários para alcançar determinados objetivos fica muito mais fácil e traz melhores resultados se for realizada em parceria com uma entidade associativa. 0 associativismo viabiliza maior participação e cria espaços de diálogo entre a sociedade organizada e o poder público (SEBRAE, 2011, p. 1).

Visto até então como um tabu, onde as relações com concorrentes são restritas, as empresas passaram a descobrir os benefícios que esta união proporciona aos seus negócios. Baseados em um princípio de 'ganha-ganha', as organizações que optam pelo associativismo percebem que este é um modo de maximizar a competitividade do grupo, também chamado de 'rede de empresas', quando trata-se de empresas com interesses em comum que se associam.

Redes de empresas são formadas por grupos de organizações com interesses comuns que se unem para a melhoria da competitividade de um determinado setor ou segmento. Esta forma de associação busca parcerias que proporcionam: competitividade, mais renda, mais lucro, agilidade, investimento acessível, informações, estudos e pesquisas, tecnologia e certificação de qualidade das empresas (SEBRAE, 2011).

Conforme Gulati, Nohria e Zaheer (2000, apud GARCIA; LIMA; CARVALHO, 2010, p. 213), uma rede de empresas refere-se "ao conjunto de relacionamentos de uma empresa com outras organizações - sejam elas fornecedores, clientes, concorrentes ou outras entidades, incluindo relacionamentos que atravessam indústrias e países" e, para estes autores, este conjunto deve ser formado por "laços internacionais duradouros, de significância estratégica para as empresas envolvidas neles"

Hoffmann, Molina-Morales e Martínez-Fernandes (2007), ao considerarem as redes como uma estrutura necessária à competitividade e à permanência das empresas no mercado, levantam uma questão pertinente: "Por que algumas empresas formam redes e outras não?".

Dalalibera (2011) vê na cultura organizacional das empresas uma possível resposta a este questionamento: "Cultura organizacional pode ser definida como um sistema de valores e crenças compartilhados que influenciam o comportamento dos participantes das organizações".

Sendo assim, algumas empresas estão mais ou menos propensas a aceitarem este tipo de associação, o que não necessariamente é imutável, principalmente naquelas que acompanham as mudanças. "Como a cultura organizacional é dinâmica, com o tempo ela tende a mudar com a interação com as outras empresas. [...] A cultura organizacional tende a ser modificada com o passar dos anos, para melhor" (DALALIBERA, 2011).

Outras formas de associativismo que podem ser citadas são as cooperativas, clusters e os consórcios, relacionados e comentados a seguir.

O cooperativismo é determinado pelo SEBRAE (2011) como uma "associação autônima de pessoas que se unem para satisfazer aspirações e necessidades econômicas, sociais e culturais comuns".

Bonassi (2003, p. 5) define em seus estudos o termo cluster como um agrupamento ou uma aglomeração de "empresas localizadas em mesma região ou localidade que desenvolvem atividades de forma articulada e com uma lógica econômica comum".

Com relação aos consórcios, estes são o agrupamento de empresas que possuem interesse(s) em comum, sem perderem sua unicidade. No que se refere ao consórcio de exportação, Paliwoda e Thomas (apud GARCIA; LIMA; CARVALHO, 2010, p. 211) consideram este uma possibilidade de 
"reunião de empresas por segmentos produtivos e/ou segmentos complementares com o objetivo de exportar seus produtos para diferentes mercados, mantendo sua própria individualidade no mercado doméstico". Para os autores, esta estratégia traz como benefício a possibilidade de concorrência com grandes fornecedores, utilizando sua eficiência e, ainda, garantindo baixos custos de produção.

Lynch (1994) ao analisar as alianças cooperativas como uma ferramenta estratégica, também elenca as desvantagens que este tipo de sistema possui, como o fato de requerer novos métodos de controle, habilidades gerenciais específicas e comprometimento de recursos. Para o autor, o inconveniente maior, no entanto, é encontrar o parceiro adequado, visto que uma combinação errada de empresas pode gerar resultados negativos para ambas.

Contudo, é importante ressaltar que não há como determinar um modelo único como sendo a 'melhor estratégia'. Conforme mencionado ao longo deste trabalho, diversas são as opções possíveis e muito depende da estrutura e planejamento e cultura da empresa. "[...] não há uma 'melhor' estratégia que se adapte a todas as circunstâncias. 0 estrategista corporativo precisa determinar a melhor arquitetura para os riscos, compensações, recursos e relações existentes" (LYNCH, 1994, p. 63).

\section{METODOLOGIA}

Metodologicamente esta pesquisa se caracteriza como aplicada, já que busca a relação entre a teoria e um benefício gerado às empresas. Além disso, possui uma abordagem quantitativa e utiliza a estatística descritiva para apresentar os resultados encontrados. Por seus objetivos, se classifica como pesquisa descritiva e por seus procedimentos, se posiciona como bibliográfica, estudo de caso e documental.

Os instrumentos de coleta de dados foram as pesquisas na empresa, entrevistas não estruturadas com os diretores do núcleo e questionário com as empresas participantes do núcleo. 0 universo da pesquisa foi de 15 empresas participantes de um Núcleo de Comércio Exterior de uma Associação Empresarial de uma cidade de Santa Catarina. A amostra pesquisada foi com o censo das associadas. As questões levantadas pelos instrumentos de coleta de dados faziam relação com práticas de internacionalização e a importância percebida do associativismo pelos empresários. 0 questionário utilizado para a pesquisa foi adaptado do material de aula da disciplina "Internacionalização de Empresas" do programa de pós-graduação da Universidade de Blumenau (FURB). Cabe esclarecer que, embora tenha sido mantido em sigilo o nome da Associação, a mesma não pertence à cidade de Blumenau.

\section{RESULTADOS}

O Núcleo de Comércio Exterior estudado foi fundado em 10 de abril de 2006 e conta atualmente com quinze empresas participantes. As empresas têm encontros de periodicidade mensal, onde discutem assuntos inerentes aos negócios internacionais das mesmas. Seu principal objetivo é possibilitar a troca de experiências e informações sobre o setor, que vive em processo de mudança.

Quanto às reuniões mensais, conforme os dados pesquisados demonstraram qualquer profissional ou empresa que tenha interesse em participar do núcleo pode acompanhar a reunião, que é aberta à comunidade corporativa.

Os principais benefícios percebidos destas reuniões, conforme demonstrou a pesquisa, foram os conhecimentos agregados, a troca de informações e aumento da rede de contatos. São desenvolvidos ao longo do ano, cursos e palestras para os associados com temas atuais, além de 
casos empresariais. Palestrantes experientes são convidados para alguns encontros, nos quais apresentam temas específicos e relevantes para o setor, como mudanças na legislação e as regras para importar e exportar no Brasil. Estes últimos também foram apontados como os grandes diferenciais do núcleo pelos entrevistados.

Cabe destacar o associativismo que acontece também internamente na Associação entre os diferentes núcleos (além do Núcleo de Comércio Exterior, a Associação possui outros 12 de temas diversos, como Têxtil, Comércio e outros). Utilizam-se, como recurso social, os representantes de outros núcleos para trocas de ideias e realização de palestras. Um exemplo bem avaliado pelos entrevistados foi a utilização de um representante do Núcleo Contábil para palestrar sobre o Radar. Este consiste em uma senha para utilizar o SISCOMEX - Sistema de Comércio Exterior, da Receita Federal, que funciona como um exame prévio das pessoas físicas e jurídicas que pretendem operar no comércio exterior (RECEITA FEDERAL DO BRASIL, 2011).

Quanto ao perfil das empresas que compõem o Núcleo de Comércio Exterior, pode-se considerar bastante heterogêneo. Participantes de diferentes áreas de atuação relacionadas ao mercado externo, incluindo importadoras, exportadoras e empresas de prestação de serviços como logística, assessoria e despacho aduaneiro. Cabe ressaltar que a teoria não reconhece a importação como uma forma de internacionalização. No entanto, por fazerem parte do núcleo, foram também levados em consideração. As empresas também são diferentes entre si no que tange o faturamento, tipos de produto, dentre outras informações relacionadas à estrutura da empresa.

Na pesquisa realizada foi possível verificar que, embora estas empresas possuam algum grau de internacionalização através de atividades relacionadas à exportação, o maior percentual de contato com o exterior acontece por meio da importação de matérias-primas.

Quadro 1 - Percentual médio de importação e exportação

\section{\% Médio de exportação das empresas: 21,33\%}

Maior \% de exportação verificado: $50 \%$

$\%$ Médio de importação das empresas: $46,6 \%$ Maior \% de importação verificado: $90 \%$

Fonte: Elaborado pelos autores

No questionário encaminhado aos participantes do núcleo, foram elencadas oito regiões geográficas, para que fossem assinaladas àquelas atendidas pela empresa. Assim foi possível determinar que esta internacionalização ocorre de modo disperso ao redor do globo entre os membros do núcleo, com destaque para o Mercosul e outros países da América Latina, e também África.

Considerando as empresas que realizam exportação como forma de envolvimento com o exterior, os seguintes números foram encontrados: 
Gráfico 1 - Grau de Internacionalização dos participantes do núcleo de Comex

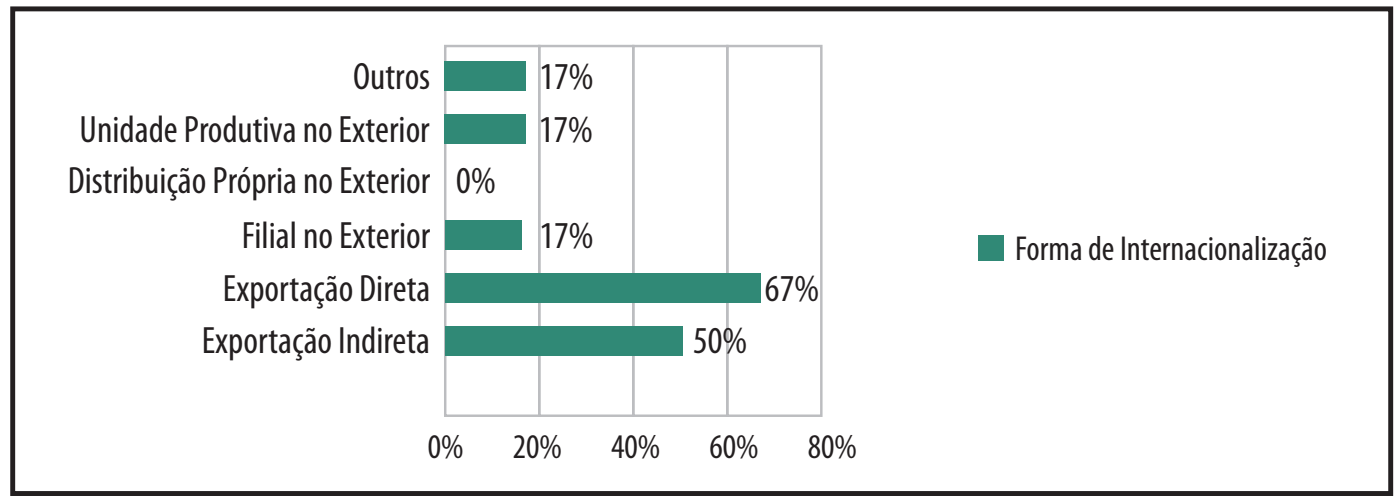

Fonte: Adaptado da disciplina de Internacionalização de Empresas, FURB.

Nota-se que a grande maioria (67\%) opta pela exportação direta de seus produtos, utilizando a estrutura de comércio exterior da própria empresa, seguida pela importação indireta através de agentes externos (50\%). Nenhuma delas possui distribuição própria no exterior, embora haja unidades de produção.

Quando questionadas sobre o desempenho, as empresas pesquisadas declararam que este é medido, principalmente, através do critério "crescimento das exportações" (66,6\%), o que mostra aparentemente a vontade que as mesmas possuem de ampliar seu faturamento e inserção no mercado externo. 0 quesito lucratividade veio logo em seguida, com $50 \%$.

A motivação para a busca pelo mercado externo também se mostra variável entre as entrevistadas. Fatores como "aproveitar uma oportunidade de negócio", "Aprendizado e desenvolvimento de competência para atuar em novos mercados" e "Busca de economias de escala" foram as principais elencadas pelas empresas do núcleo. Não foram assinaladas por nenhum participante as opções: "Saturação do mercado brasileiro", "entrada/ameaça de empresas internacionais no mercado interno" e "Apoio de programas governamentais de fomento à internacionalização".

Isto demonstra que não são questões relativas ao mercado nacional que motivam a internacionalização. A exceção fica por parte de um problema interno que foi o mais destacado no quesito "Barreiras à Internacionalização": a Burocracia, unânime entre os participantes.

Outro item foi relacionado à questão mercadológica: o marketing internacional, salientado por $83 \%$ da pesquisa. Na opinião das empresas, o principal diferencial de seus produtos destinados à exportação refere-se à qualidade (80\%) e flexibilidade (60\%) dos mesmos.

Isto pode estar relacionado à forma com que as empresas lidam com a imagem de seus produtos no exterior ou com a própria forma de negociação. Nenhuma das empresas declarou ter criado poucas linhas de produtos. Consideraram que criaram linhas suficientes e realizaram mudanças moderadas para que fossem atendidas as exigências do mercado externo.

Esta pode ser uma consequência do próprio mercado e do ambiente, tanto nacional quanto internacional, em que as empresas operam. Foi solicitado às entrevistadas que numerassem de 1 a 7 os itens do quadro abaixo, relacionados à visão de ambiente que as mesmas possuem. Os resultados aparecem acima da linha horizontal. 
Quadro 2 - Ambiente em que a empresa está inserida.

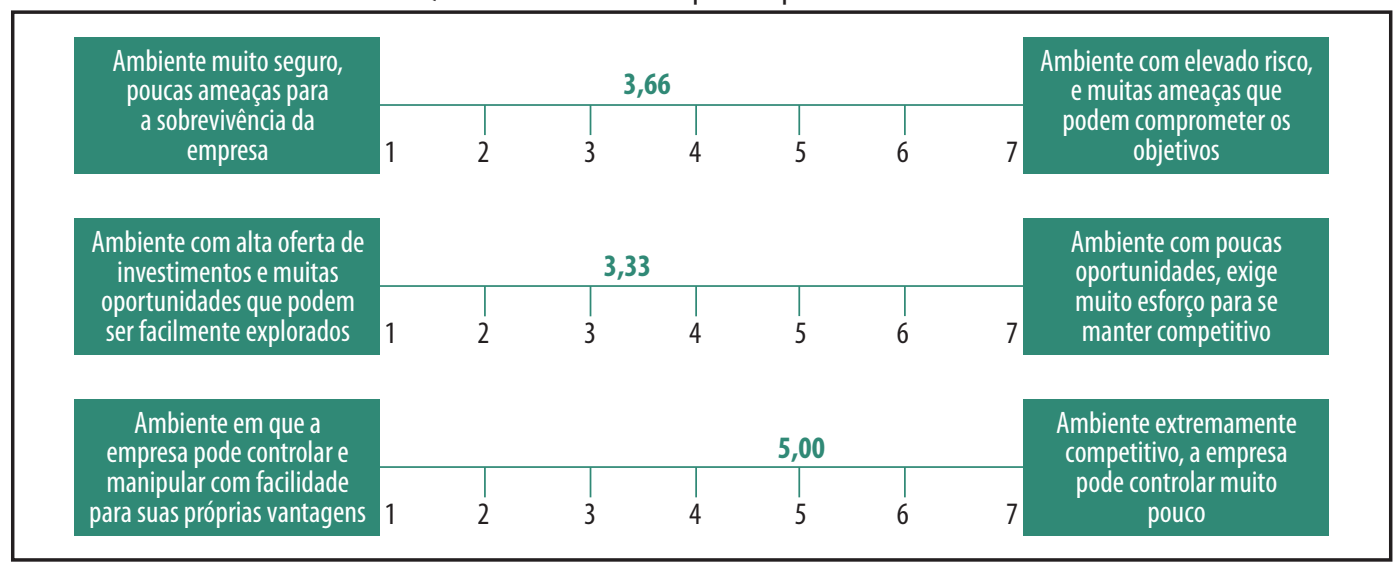

Fonte: Adaptado da disciplina de Internacionalização de Empresas, FURB.

As respostas apresentadas mostram-se consonantes ao padrão de risco moderado optado pelas empresas. A questão média de segurança no ambiente e média oferta de oportunidades pode estar diretamente relacionada à forma de conduta da empresa perante o mercado e riscos de internacionalização.

Estas empresas, não obstante, tem noção de que seu crescimento e fortalecimento no mercado externo podem depender, ou ser consolidado, através de parcerias realizadas, tanto a nível nacional quanto internacional. As respostas fornecidas quanto à importância de parcerias variaram sempre entre 6 e 7, em uma escala de 1 a 7 . Um total de $66,6 \%$ afirma que pretende expandir suas parcerias, enquanto $33,3 \%$ pretende apenas manter as parcerias atuais.

A busca pelas parcerias foi um item com uma das maiores variações nas respostas obtidas, conforme verificado no quadro 3 a seguir:

Quadro 3 - Análise da qualidade da rede de relacionamentos.

Procura eliminar parcerias ineficazes e substituir por outras mais eficazes:

Apenas corta parcerias que não estão atingindo as expectativas:

Apenas aumenta o número de parcerias que efetivamente contribuam com a

internacionalização da minha empresa:

As parcerias atuais estão adequadas, não há necessidade de mudanças:

Outras situações:
$33,3 \%$

$16,6 \%$

$33,3 \%$

$0 \%$

$16,6 \%$

Fonte: Adaptado da disciplina de Internacionalização de Empresas, FURB.

Variável também foi o tipo de parceria que cada empresa possui: $50 \%$ possui apenas parcerias simples, $17 \%$ informaram possuir parcerias complexas, e outras $33 \%$ parcerias vitais, sem as quais a internacionalização seria comprometida. Deste modo, não é possível determinar um padrão ou média para os participantes do núcleo pesquisado.

No entanto, considerando exclusivamente o envolvimento destas empresas com a Associação, em especial o Núcleo de Comércio Exterior à qual o grupo pertence, $50 \%$ afirma que esta parceria facilita o processo de internacionalização, 16,6\% não considera o núcleo como um facilitador, e 33,3\% acredita que facilita, em termos, indiretamente. 


\section{CONCLUSÃO}

O presente artigo teve o objetivo de analisar o Núcleo de Comércio Exterior de uma Associação Empresarial de uma cidade de Santa Catarina no que tange à sua estrutura, estratégias, mas, principalmente, a utilização da internacionalização e do associativismo como forma de se consolidar no mercado externo.

A pesquisa bibliográfica de nível macro foi realizada com referências e autores reconhecidos e focou a administração, bem como as principais teorias que a norteiam. Foi direcionada especialmente à parte do comércio exterior, apresentando um panorama do mercado nacional. Nesta etapa, a fundamentação buscou o assunto específico da internacionalização e do associativismo e desenvolveu a proposta de ação.

Com o conjunto de técnicas utilizadas, foi possível estabelecer um perfil do núcleo como um todo, pois não foram analisados os dados fornecidos pelas empresas individualmente. Assim, foi possível caracterizar o Núcleo de Comércio Exterior como um grupo que possui bastante envolvimento com o mercado externo. No entanto, suas ações são mais voltadas à importação do que a exportação. 0 nível de internacionalização tende a não ser elevado. No entanto, aqueles que declararam trabalhar com internacionalização, confirmaram que o associativismo é vital para seus negócios.

Quanto ao associativismo, não apenas por formarem o Núcleo de Comércio Exterior, as empresas acreditam na importância das parcerias. Seja no mercado interno ou externo, seja na troca de informações ou parcerias de negócios, o associativismo contribui com o andamento nos negócios e as empresas declararam que pretendem continuar esta expansão.

\section{ASSOCIATIONISM AS A STRATEGY OF BUSINESS INTERNATIONALIZATION: A CASE STUDY FROM AN ASSOCIATION OF SANTA CATARINA}

\section{ABSTRACT}

This case study presents the situation of the foreign trade department of a business association from Santa Catarina and its importance to the companies that participate in it. The creation of departments in associations stimulates the discussion between companies from the same sector about issues in common and the planning of strategies to be adopted by the group. The foreign trade department studied here has 15 participants who meet twice a month. The meetings enable debate and the sharing of experiences. Some main items from the department's strategic planning are cited to verify the importance of the association networks in internationalization. The bibliographic review focused on two main theories: internationalization and its different modalities; and the association as a strategic choice to aggregate value in business. The empirical research was done through interviews with the foreign trade department representatives, survey with the companies of the department and by comparing studies and the practices carried out by the association. As a main result, considering the sample studied, it became evident that association is relevant in the processes of internationalization of the companies.

Keywords: Strategic Choice. Business Internationalization. Association. 


\section{REFERÊNCIAS}

ABIT. Consórcio de Exportação. [2011]. Disponível em: <http://www.abit.org.br/texbrasil/ consorcio/oquee.shtml>. Acesso em: 20 set. 2011.

ABF. A ABF e ESPM lançam estudo sobre internacionalização. [2010]. Disponível em: $<\mathrm{http} / / /$ www.portaldofranchising.com.br/site/content/interna/index.asp?codA=35\&codAf= 378\&codC=3\&origem>. Acesso em: 07 dez. 2010.

ARMANDO, E. Competitividade internacional em têxteis. 171 f. Dissertação (Mestrado em Administração) - Universidade de São Paulo, São Paulo, 2003.

BATEMAN, Thomas S; SNELL, Scott A. Administração: Construindo vantagem competitiva. São Paulo: Atlas, 1998.

BONASSI, Fabio Angelo. 0 associativismo como estratégia competitiva no varejo: um estudo de caso na Aremac-AM - Associação Regional de Empresas de Material de Construção da Alta Mogiana. Revista Eletrônica de Administração, v. 2, n. 03, jul./dez., 2003.

BRASIL. Ministério do Desenvolvimento, Indústria e Comércio Exterior. [2011]. Comércio Exterior. Disponível em: <http://www.mdic.gov.br>. Acesso em: 10 out. 2011.

CIELO, Ivanete Daga et al. Associativismo: união de pessoas por um objetivo comum. Projeto Gerart, 2009. Apostila.

DUNNING, J. H. The ecletic paradigm of international production: a restatement and some possible extensions. Journal of International Marketing Business Studies, v. 19, n. 1, p. 131, Spring, 1988.

DALALIBERA, Pedro. Rede de Empresas. [2011]. Disponível em:

<http://www.rededeempresas.com.br/blog/2011/03/cultura-organizacional-e-as-redes-deempresas/> Acesso em: 20 ago. 2011.

FILATOTCHEV, I.; STEPHAN, J.; JINDRA, B. Ownership structure, strategic controls and export intensity of foreign-invested firms in transition economies. Journal of International Business Studies, v. 39, p. 1133-1148, 2008.

FUNDAÇÃO DOM CABRAL. Internacionalização. [2011]. Disponível em: <http://www.fdc. org.br>. Acesso em: 20 set. 2011.

GARCIA, Sheila Farias Alves; LIMA, Gustavo Barbieri; CARVALHO, Dirceu Tornavoi. Redes interorganizacionais de Cooperação para a Internacionalização. REGE - Revista de Gestão, São Paulo, v.17, n.2, p. 209-224, abr./jun. 2010.

HOFFMANN, V. E.; MOLINA-MORALES, F. X.; MARTÍNEZ-FERNÁNDEZ, T. Redes de Empresas: Proposta de uma tipologia para classificação aplicada na indústria de cerâmica de revestimento. Revista de Administração Contemporânea, p. 103-127, 2007.

HYMER, S. The internationalization of capital. Journal of Economic Issues, v. 6, n.1, p. 91111, Mar. 1972. 
IBRASS. Associativismo. [2011]. Disponível em: <http://ibrass.org>. Acesso em: 21 ago. 2011.

LAMPERT, Adriana. Franquias. [2011]. Disponível em:

<http://jcrs.uol.com.br/site/noticia.php?codn=75866>. Acesso em: 12 nov. 2011.

LEVITT, T. Globalization of Markets. Harvard Business Review, p. 92-102, May/June, 1983.

LOPEZ, José Manoel; GAMA, Marilza. Comércio Exterior Competitivo. São Paulo: Aduaneiras, 2008

LYNCH, R. P. Alianças de Negócios: uma arma secreta, inovadora e oculta para vantagens competitivas. São Paulo: Makron Books, 1994.

MELÉNDEZ, E.; HAWLEY, J.; McCORMICK, L. The interest of business: business associations and workforce development collaboration. International Journal of Business and Social Science, v. 3, n. 1, Jan. 2012.

MINERVINI, Nicola. 0 exportador: ferramenta para atuar com sucesso nos mercados internacionais. 3.ed. São Paulo: Makron Books, 2001.

MIRANDA, Maria Bernadete; MALUF, Clovis Antonio. 0 contrato de joint venture como instrumento jurídico de internacionalização das empresas. [2011]. Disponível em: <http://www.clovismaluf.com.br/artigos/artigo00.htm> Acesso em: 20 set. 2011.

PENG, M.W. The resouce-based view and International business. Journal of Management, v. 27, n. 6, p. 803-829, 2001.

PENROSE, E. The Theory of the Growth of the Firm. Oxford: Oxford University Press, 1959 PORTER, Michael E. Vantagem Competitiva. Rio de Janeiro: Campus, 1989.

PORTER, Michael E. Estratégia Competitiva: técnicas para análise de indústrias e da concorrência. 2.ed. Rio de Janeiro: Elsevier, 2004.

RECEITA FEDERAL DO BRASIL. [2011]. Comércio Internacional. Disponível em: <http://www.receita.fazenda.gov.br>. Acesso em: 09 out. 2011.

RUIGROK, W.; WAGNER, H. Internationalization and Performance: and organizational leaning perspective. Management International Review, v.1, n.43, p.63-68, 2003.

SEBRAE. Associativismo. [2011]. Disponível em: <http://www.sebrae.com.br>. Acesso em: 02 set. 2011. 